\title{
Lung cancer mortality in Europe and the USA between 2000 and 2017: an observational analysis
}

\author{
Chinmay Jani $\mathbb{1}^{1,2}$, Dominic C. Marshall ${ }^{3}$, Harpreet Singh ${ }^{4}$, Richard Goodall ${ }^{5}$, Joseph Shalhoub ${ }^{5,6}$, \\ Omar Al Omari ${ }^{1,2}$, Justin D. Salciccioli $\mathbb{C}^{2,7,9}$ and Carey C. Thomson ${ }^{1,2,8,9}$
}

${ }^{1}$ Dept of Medicine, Mount Auburn Hospital/Beth Israel Lahey Health, Cambridge, MA, USA. ${ }^{2}$ Harvard Medical School, Boston, MA, USA. ${ }^{3}$ National Heart and Lung Institute, Imperial College London, London, UK. ${ }^{4}$ Dept of Pulmonary and Critical Care, Medical College of Wisconsin, Milwaukee, WI, USA. ${ }^{5}$ Dept of Surgery and Cancer, Imperial College of London, London, UK. ${ }^{6}$ Imperial Vascular Unit, Imperial College Healthcare NHS Trust, London, UK. 'Division of Pulmonary and Critical Care, Brigham and Women's Hospital, Boston, MA, USA. ${ }^{8}$ Division of Pulmonary and Critical Care, Mount Auburn Hospital, Cambridge, MA, USA. ${ }^{9}$ These authors contributed equally.

Corresponding author: Chinmay Jani (chinmay.jani@mah.harvard.edu)

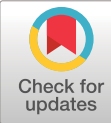

This version is distributed under the terms of the Creative Commons Attribution NonCommercial Licence 4.0. For commercial reproduction rights and permissions contact permissions@ersnet.org

Received: 4 May 2021 Accepted: 27 Sept 2021

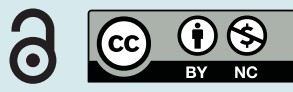

Shareable abstract (@ERSpublications)

Lung cancer mortality trends have steadily decreased for males between 2000 and 2017 in Europe and the USA, whereas increasing mortality trends have been observed for females. Investigation into the gender mortality gap is called for. https://bit.ly/2WDq8rN

Cite this article as: Jani C, Marshall DC, Singh H, et al. Lung cancer mortality in Europe and the USA between 2000 and 2017: an observational analysis. ERJ Open Res 2021; 7: 00311-2021 [DOI: 10.1183/ 23120541.00311-2021].

\section{Abstract}

Background The lung is the most common site for cancer and has the highest worldwide cancer-related mortality. Our study reports and compares trends in lung cancer mortality in the USA and 26 European countries.

Study design and methods Lung cancer mortality data were extracted for males and females for each of the years 2000-2017 from the World Health Organization (WHO) Mortality and the Centers for Disease Control and Prevention (CDC) WONDER databases. Lung cancer mortality trends were compared using Joinpoint regression analysis, and male-to-female mortality ratios were calculated.

Results Down-trending lung cancer mortality rates were observed in males in all countries except Cyprus and Portugal between 2000 and 2017. In females, increasing mortality rates were observed in 22 of the 27 countries analysed. Latvia had the highest estimated annual percentage change (EAPC) in male mortality (-9.6\%) between 2013 and 2015. In the USA, EAPCs were $-5.1 \%$ for males and $-4.2 \%$ for females between 2014 and 2017. All countries had an overall decrease in the ratio of male-to-female lung cancer mortality. The most recent observation of median male-to-female mortality was 2.26 (IQR 1.92-4.05). The countries with the greatest current sex disparity in lung cancer mortality were Lithuania (5.51) and Latvia (5.00).

Conclusion Between 2000 and 2017, lung cancer mortality rates were decreasing for males in Europe and the USA, whereas increasing lung cancer mortality rates were generally observed in females. There is a persistent but decreasing sex-mortality gap, with men having persistently greater lung cancer mortality but with rates decreasing faster than women.

\section{Introduction}

Lung cancer is the leading cause of cancer death in males and the third most diagnosed and second leading cause of cancer death in females worldwide. In the USA, lung cancer is the most common cancer and the leading cause of cancer deaths in males and females [1,2]. The World Health Organization (WHO) estimated that, in 2018, there were 2.09 million cases of lung cancer and 1.76 million lung cancer-related deaths annually worldwide [3]. Overall, there has been a worldwide decline in the incidence of lung cancer $[4,5]$. However, multiple European studies have reported incongruous falls in lung cancer incidence in males versus females $[4,5]$. Up-to-date comparisons of the recent trends in lung cancer mortality across the European Union (EU), the UK and the USA are lacking.

The principal aim of this study was to compare the trends in mortality from lung cancer across the USA and EU countries over recent decades, using data obtained from the Centers for Disease Control and 
Prevention Wide-ranging ONline Data for Epidemiologic Research (CDC WONDER) and the WHO Mortality Databases. A secondary aim was to compare the differential trends amongst males and females within each analysed country to identify sex disparities in temporal lung cancer mortality trends. We have previously used similar methods to describe trends in mortality from cardiovascular [6] and respiratory diseases $[7,8]$.

\section{Methods}

\section{Data sources}

Data were obtained from two publicly available online databases: CDC WONDER for the USA, and the WHO Mortality Database for the 27 EU countries (inclusive of the UK).

Lung cancer mortality data were identified and extracted from the WHO database from 2000 to 2017 using the International Classification of Diseases (ICD) system code C34 ("Malignant neoplasm of bronchus and lung”) and its sub-codes. The WHO evaluates the quality of the data to ensure comparability and reliability without adjustment for underreporting [9]. Luxembourg and Malta were excluded based on the data quality and multiple missing data points for $>3$ consecutive years. Twenty-five member states of the EU, the UK and the USA were selected to produce a defined group for analysis [10]. WHO Mortality lacks data for the USA after the year 2007. Therefore, the CDC Wonder database was used for the USA.

Lung cancer mortality data for individuals in the USA were extracted from the CDC WONDER database in collaboration with the National Center for Health Statistics and the Vital Statistics Cooperative Program [11]. CDC WONDER is a comprehensive online public health information system developed and owned by the CDC and its collaborating partners to serve public health practice and research [12, 13]. The mortality database is updated annually from deaths registered by national civil registration systems. Data is collected according to ICD tenth revision, a process that has been used previously with adequate validity and the provision of robust data $[6,8]$.

Crude mortality rates were dichotomised by sex and reported by year. We computed age-standardised death rates (ASDRs) per 100000 population using the World Standard Population for Europe and the US Standard Population for the USA. The ASDR was defined as mortality weighted to the distribution of mortality per 5-year age group, according to the appropriate standard population [14]. This removes the effects of historical events on age structure and controls for differences in age structure in populations. The estimated level of coverage for deaths with a recorded cause for death is calculated by actual reporting divided by the estimated mortality rate. Population and birth recording in all countries exceed $90 \%$, as per the WHO standard for inclusion in the database [9]. Institutional review board approval was not necessary as the data collected are available in the data-repositories mentioned above in a de-identified format.

\section{Statistical analyses}

Joinpoint regression analysis with annualised data (between 2000 and 2017, where available) was used to assess changes in linear slope for mortality trends over time. In brief, Joinpoint analysis assesses the overall trends in mortality, initially with no Joinpoints, and tests for significant changes in the model with the sequential addition of Joinpoints where there is a significant change in the slope of the line. Joinpoint software (Command Line Version 4.5.0.1) is provided by the US National Cancer Institute Surveillance Research Program [15]. The model computes an estimated annual percentage change (EAPC) for each trend by fitting a regression line to the natural logarithm of the rates. Mortality data were missing in a small subset of countries in the WHO Mortality Database for one or more calendar years. Joinpoint software requires continuous data throughout the observation period to be suitable for analysis. Therefore, we imputed using the last observation carried forward for countries with missing data for the purpose of Joinpoint analysis only. If a country had $>3$ consecutive years of missing data during the observation period, this was excluded from the analysis to avoid excess imputation. There were no other modifications to the data. Changes in ASDR over the observation period are calculated as crude absolute differences between first and last data points for the earliest and most recent years available.

Post hoc analysis

From our primary analysis, we observed convergent trends in male and female mortality during the observation period across all countries. Given the magnitude and changing trends for males and females, a post hoc analysis was performed to assess the changing magnitude of this male-to-female mortality difference. We computed male-to-female mortality ratios and used locally weighted scatterplot smoothing (LOWESS) plots fit to the ratios of male-to-female mortality using SAS v9.4 (SAS, Cary, NC, USA). We plotted the results of this analysis for visual inspection. As this was a post hoc analysis, we treated this as exploratory and descriptive, with no further tests of the data performed. 
Results

Data from a total of 27 countries were analysed (25 EU nations (inclusive of the UK) and the USA). Six countries had complete data for each of the years 2000-2017, 12 had data from 2000 to 2016, seven countries had data from 2000 to 2015 and two countries had data from 2000 to 2014, accounting for a total of 898 data elements available for analysis. For the purpose of Joinpoint analysis alone, 14 (1.6\%) data points were imputed for missing data points, as described above.

\section{Current lung cancer mortality}

Table 1 and figure 1 show the most recent calendar year mortality data. In 2017, Hungary had the highest observed lung cancer ASDR of all analysed countries for both males and females, 64.51/100 000 and $31.04 / 100$ 000, respectively. In 2017, the lowest lung cancer mortality rate was observed in Sweden for males (17.31/100 000) and Lithuania for females (7.58/100 000). ASDRs for the USA in 2017 for males and females were 44.30/100 000 and 30.60/100 000, respectively.

\section{Changes in lung cancer mortality between 2000 and 2017}

Table 1 and figures 1 and 2 show lung cancer mortality rates at the beginning and the end of the study period. The overall trend for lung cancer mortality for males across Europe and the USA was decreasing steadily over time. Mortality rates in males decreased in the majority of the included countries, with the only exceptions being Bulgaria (+3.45\%), Portugal $(+1.60 \%)$ and Romania $(+0.03 \%)$. The largest decreases in male mortality in European countries were observed in the Czech Republic ( $-27.34 \%)$ and Hungary (-20.30\%). The USA showed a decrease of 32.40\% in male mortality between 2000 and 2017. In contrast to males, the majority of the analysed countries had an increase in lung cancer mortality rates

TABLE 1 Age-standardised death rate in males and females

\begin{tabular}{|c|c|c|c|c|c|c|c|c|}
\hline \multirow[t]{3}{*}{ Country } & \multicolumn{3}{|c|}{ Start point } & \multicolumn{3}{|c|}{ End point } & \multirow{2}{*}{\multicolumn{2}{|c|}{$\begin{array}{l}\text { Overall } \\
\text { percentage } \\
\text { change in } \\
\text { mortality }\end{array}$}} \\
\hline & \multirow[t]{2}{*}{$\begin{array}{l}\text { Year of } \\
\text { diagnosis }\end{array}$} & \multirow[t]{2}{*}{$\begin{array}{l}\text { Age adjusted } \\
\text { rate in males }\end{array}$} & \multirow[t]{2}{*}{$\begin{array}{l}\text { Age adjusted rate } \\
\text { in females }\end{array}$} & \multirow[t]{2}{*}{$\begin{array}{c}\text { Year of } \\
\text { diagnosis }\end{array}$} & \multirow[t]{2}{*}{$\begin{array}{l}\text { Age adjusted } \\
\text { rate in males }\end{array}$} & \multirow[t]{2}{*}{$\begin{array}{l}\text { Age adjusted rate } \\
\text { in females }\end{array}$} & & \\
\hline & & & & & & & Males & Females \\
\hline Austria & 2000 & 38.92 & 12.35 & 2017 & 28.44 & 14.80 & -10.48 & 2.45 \\
\hline Belgium & 2000 & 60.63 & 11.30 & 2016 & 40.40 & 16.80 & -20.23 & 5.50 \\
\hline Bulgaria & 2000 & 38.38 & 6.83 & 2015 & 41.83 & 9.51 & 3.45 & 2.68 \\
\hline Croatia & 2000 & 74.09 & 12.51 & 2016 & 54.79 & 15.48 & -19.30 & 2.97 \\
\hline Cyprus & 2004 & 28.28 & 4.25 & 2016 & 25.74 & 8.34 & -2.54 & 4.09 \\
\hline Czech Republic & 2000 & 63.27 & 12.88 & 2017 & 35.93 & 14.76 & -27.34 & 1.88 \\
\hline Denmark & 2000 & 46.79 & 28.77 & 2015 & 33.43 & 29.65 & -13.36 & 0.88 \\
\hline Estonia & 2000 & 60.96 & 6.91 & 2016 & 42.69 & 10.26 & -18.27 & 3.35 \\
\hline Finland & 2000 & 35.13 & 8.65 & 2016 & 25.54 & 11.07 & -9.59 & 2.42 \\
\hline France & 2000 & 47.25 & 7.80 & 2014 & 41.02 & 14.08 & -6.23 & 6.28 \\
\hline Germany & 2000 & 43.77 & 11.45 & 2016 & 32.79 & 16.50 & -10.98 & 5.05 \\
\hline Greece & 2000 & 52.28 & 8.18 & 2016 & 50.09 & 11.77 & -2.19 & 3.59 \\
\hline Hungary & 2000 & 84.81 & 23.24 & 2017 & 64.51 & 31.04 & -20.30 & 7.80 \\
\hline Ireland & 2000 & 43.44 & 20.41 & 2015 & 30.44 & 20.05 & -13.00 & -0.36 \\
\hline Italy & 2000 & 49.62 & 9.27 & 2015 & 36.25 & 12.20 & -13.37 & 2.93 \\
\hline Latvia & 2000 & 57.75 & 6.12 & 2015 & 41.72 & 8.34 & -16.03 & 2.22 \\
\hline Lithuania & 2000 & 55.35 & 5.49 & 2017 & 41.78 & 7.58 & -13.57 & 2.09 \\
\hline Netherlands & 2000 & 55.59 & 17.69 & 2016 & 38.22 & 24.79 & -17.37 & 7.10 \\
\hline Poland & 2000 & 69.87 & 13.13 & 2016 & 53.00 & 18.95 & -16.87 & 5.82 \\
\hline Portugal & 2000 & 29.66 & 5.44 & 2016 & 31.26 & 7.70 & 1.60 & 2.26 \\
\hline Romania & 2000 & 47.43 & 8.11 & 2017 & 47.46 & 11.71 & 0.03 & 3.60 \\
\hline Slovakia & 2000 & 62.25 & 8.59 & 2014 & 42.14 & 10.72 & -20.11 & 2.13 \\
\hline Slovenia & 2000 & 54.44 & 11.02 & 2015 & 43.42 & 15.88 & -11.02 & 4.86 \\
\hline Spain & 2000 & 48.82 & 5.12 & 2015 & 41.04 & 9.61 & -7.78 & 4.49 \\
\hline Sweden & 2000 & 22.43 & 14.19 & 2016 & 17.31 & 15.67 & -5.12 & 1.48 \\
\hline UK & 2001 & 42.06 & 21.49 & 2016 & 30.66 & 22.05 & -11.40 & 0.56 \\
\hline USA & 2000 & 76.70 & 41.30 & 2017 & 44.30 & 30.60 & -32.40 & -10.70 \\
\hline
\end{tabular}

Luxembourg and Malta were excluded due to data quality. ". USA data are standardised based on US population. CDC WONDER database is used for data collection in the USA. 
among females. Only in Ireland $(-0.36 \%)$ and the USA $(-10.70 \%)$ were decreased lung cancer mortality rates observed for females. All remaining countries had increasing lung cancer mortality rates for females, with the highest increases observed in Hungary (+7.80\%) and the Netherlands (+7.10\%).

Joinpoint regression for changes in lung cancer mortality trends in males

Table 2 and figure 2 show the results of the Joinpoint regression analysis for lung cancer mortality rates in males from 2000 to 2017. Significant trend changes were observed. The most rapid decreases in lung cancer mortality rates were identified in Latvia between 2013-2015 (EAPC -9.6\%), followed by Belgium between 2010 and 2016 (EAPC -4.2\%), Austria between 2013-2017 (EAPC -3.5\%), Italy between 2012-2015 (EAPC -3.3\%) and Greece between 2014-2016 (EAPC -3.2\%). Male mortality declined consistently across the study period, with only one Joinpoint in Czech Republic, Denmark, Estonia, Finland, Hungary, Ireland, Lithuania, Slovakia, Slovenia, the UK, and the Netherlands. Bulgaria, Romania, Spain, and Sweden also showed increased mortality in the initial years of the investigation, followed by a subsequent downward trend. Greece showed a notable trend with three Joinpoints; there was a steady decline until 2011 (EAPC -0.4\%), followed by increasing mortality between 2011 and 2014 (EAPC $2.8 \%$ ), and the second period of decline after 2014 (EAPC -3.2\%). Spain and Germany also demonstrated more variable trends with three Joinpoints over the time period studied, and both with significant reductions in lung cancer mortality over the periods covered by the most recent trends (Spain between 2011-2015, EAPC -2.3\%; Germany between 2013-2016, EAPC -2.5\%. The United States had variable trends in lung cancer mortality for males, with four Joinpoints identified and a steady decline in mortality since 2000, followed by a more rapid decline recently (EAPC $-5.1 \%, 2014-2017$ ).

Joinpoint regression for changes in lung cancer mortality trends in females

Table 2 and figure 2 show the results of a Joinpoint regression analysis for lung cancer mortality rates in females between 2000 and 2017 for each included country. For females, 21 of the 26 European nations reported increasing rates in lung cancer mortality, with the exceptions being Belgium, Denmark, Ireland, Sweden and the UK. Sweden, Ireland and Denmark showed declining mortality rates from 2005 to 2006, the UK from 2008, whereas Belgium did not show a decreasing mortality trend until 2011. The highest EAPC (+4.4\%, 2000-2015) is noted in Spain. The greatest recent decline in mortality was in Denmark, with an EAPC of $-0.9 \%$ (2005-2015). The USA had four Joinpoints for females, in a pattern similar to that observed for males. The USA had an increase in mortality from the year 2000 to $2004(+0.2 \%)$, followed by a steady decline. Like males, female mortality rates have also declined recently $(-4.2 \%$, 2014-2017).

Post hoc analysis of the male-to-female ratio of lung cancer mortality

Table 4 and figure 3 show sex ratio trends for lung cancer. Lung cancer mortality rates were higher in males than females in all countries for each year of comparison. Over the observation period, all countries had an overall decrease in the ratio of male-to-female mortality: in 2000, the median male-to-female mortality ratio was 5.35 (IQR 3.65-6.06), whereas, for the most recent year, the median male-to-female mortality ratio was 2.26 (IQR 1.92-4.05). The countries with the greatest current disparity in lung cancer mortality by sex were Lithuania (male-to-female mortality ratio 5.51), Latvia (5.00) and Bulgaria (4.40). The countries with the smallest differences in mortality between sex were Sweden (male-to-female mortality ratio 1.10), Denmark (1.13) and the UK (1.39). The median percentage change for all countries was $-44.45 \%$ (IQR $-50.44 \%$ to $-30.56 \%$ ). The countries with the greatest percentage change in malefemale lung cancer mortality ratios were Spain $(-55.19 \%)$, Belgium $(-55.18 \%)$ and Cyprus $(-53.64 \%)$. The countries with the smallest percentage change in male-female lung cancer mortality ratios were Bulgaria (-21.65\%), the USA (-22.05\%) and Portugal (-25.46\%).

\section{Discussion}

Principal findings

In this observational study of lung cancer mortality in Europe and the USA, male lung cancer mortality steadily declined in the majority of countries. However, for females, there were increasing lung cancer mortality trends in the majority of countries. The USA was a notable exception to this observation, with decreasing lung cancer mortality rates observed in females over the 17-year study period. There remains a persistent sex-mortality gap from lung cancer, with male mortality rates remaining consistently higher than those for females. However, the magnitude of these differences in male-female lung cancer mortality ratios is decreasing over time, resulting from both general decreases in male lung cancer mortality rates and increases in female lung cancer mortality rates.

The primary aim of this investigation was to investigate the changes in trends in lung cancer mortality between males and females over the past two decades and provide up-to-date estimates of the burden of 


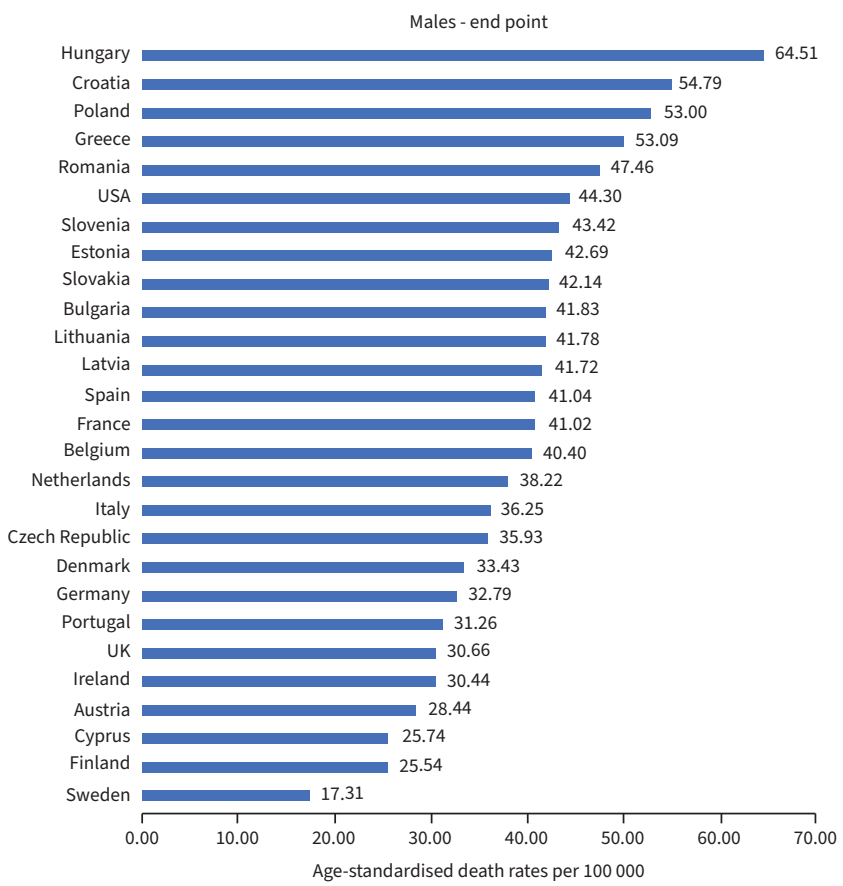

Percentage change in male mortality

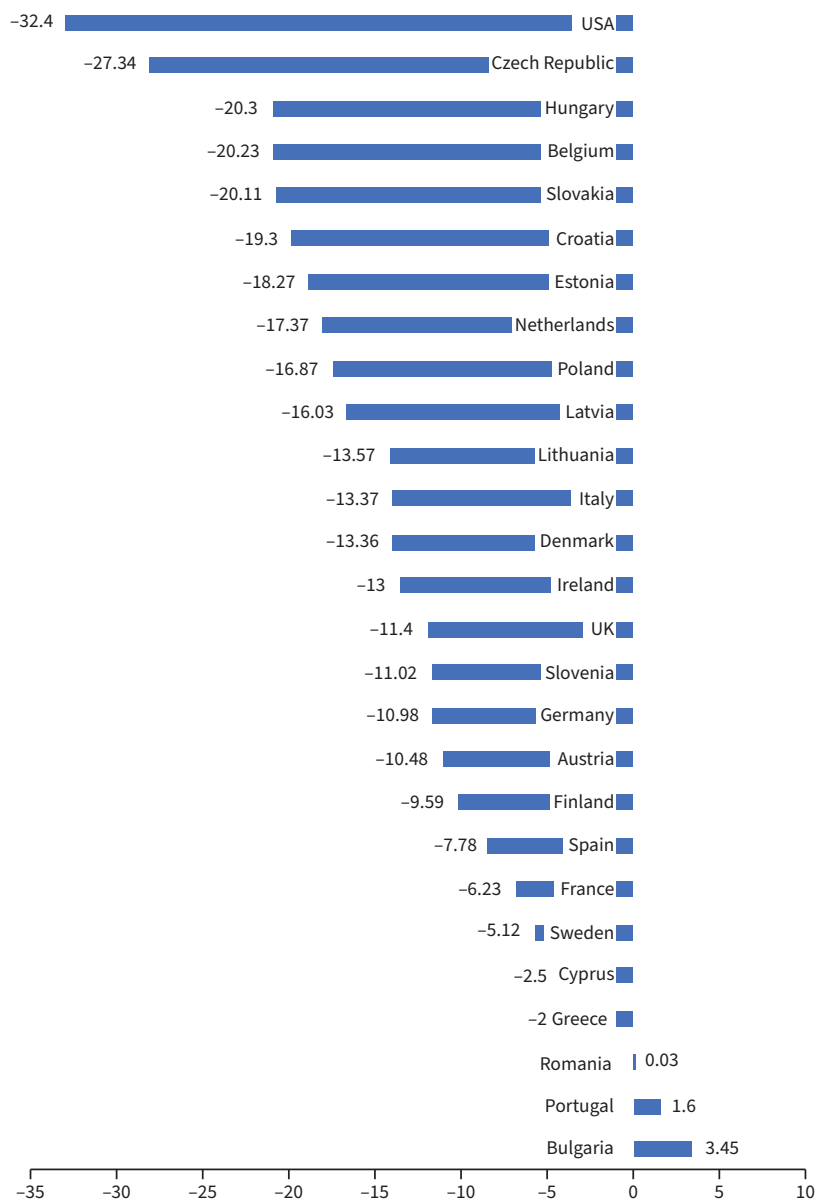

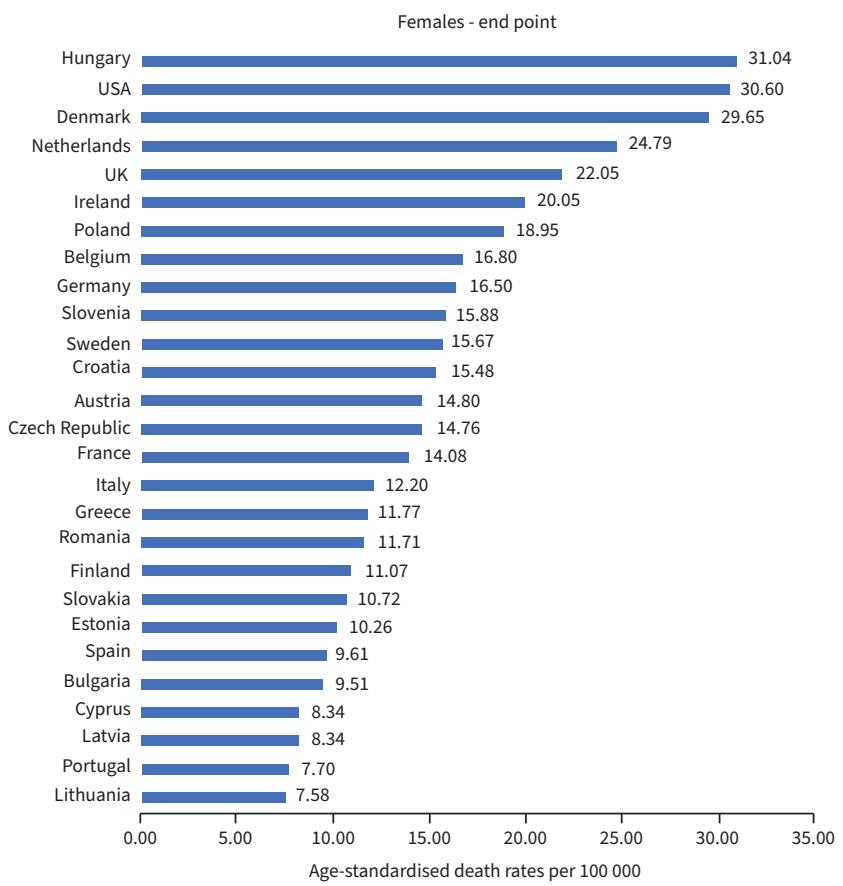

Percentage change in female mortality

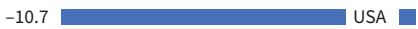

-0.36 Ireland

$$
\text { UK } \square .56
$$

Denmark 0.88

Sweden 1.48

Czech Republic 1.88

Lithuania 2.09

Slovakia 2.13

Latvia 2.22

Portugal 2.26

Finland 2.42

Austria 2.45

Bulgaria 2.68

Italy 2.93

Croatia 2.97

Estonia 3.35

Greece $\quad 3.59$

Romania 3.6

Cyprus 4.09

Spain 4.49

Slovenia 4.86

Germany 5.05

Belgium 5.5

Poland 5.82

France 6.28

Netherlands 7.1

Hungary 7.8

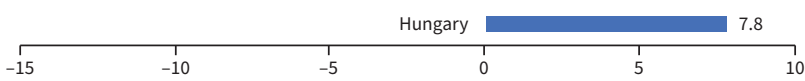

FIGURE 1 Lung cancer age-standardised death rates for males and females. 

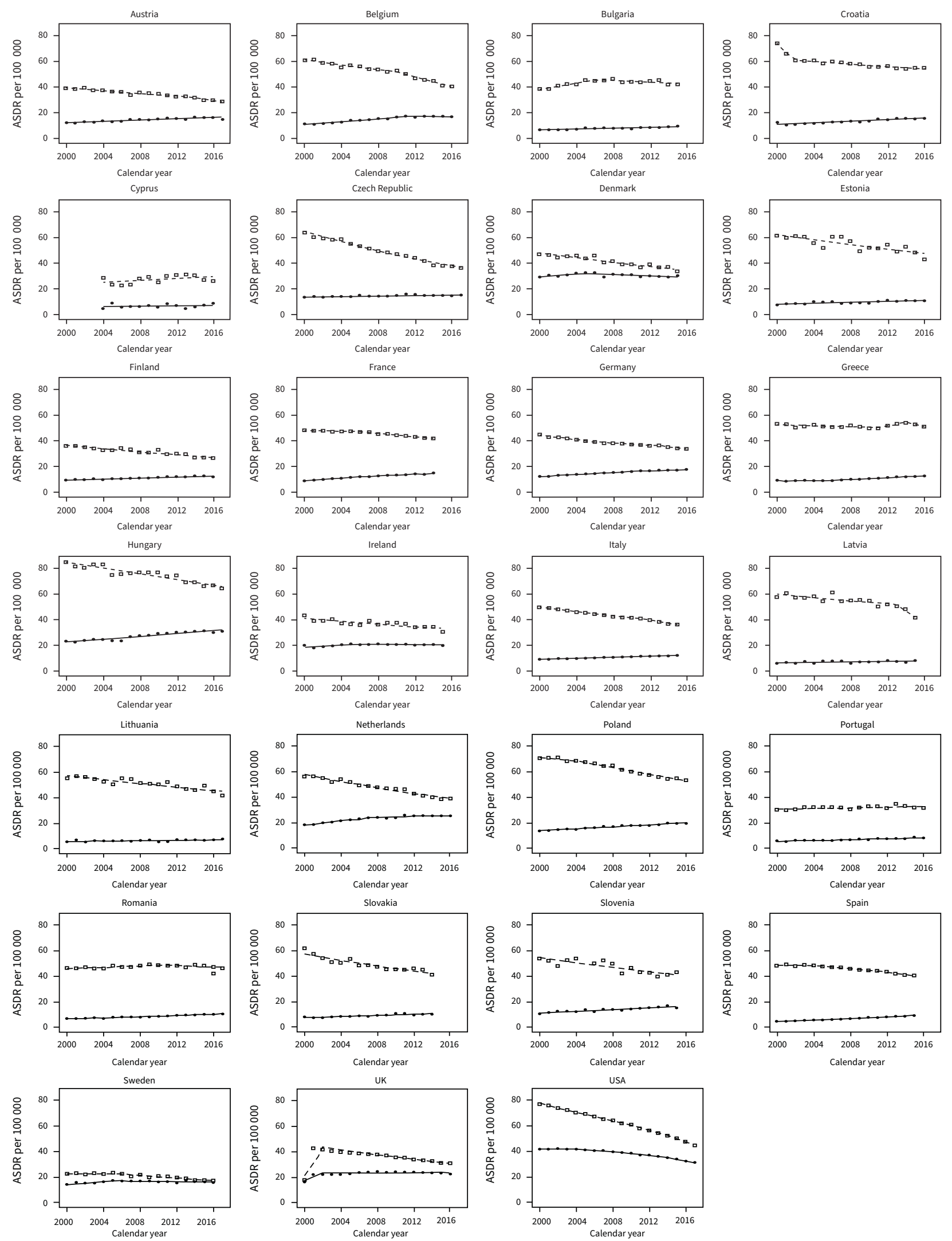

FIGURE 2 Trends in age-standardised death rates (ASDRs) per 100000 for lung cancer. Squares indicate male mortality; circles indicate female mortality. 


\begin{tabular}{|c|c|c|c|c|c|c|c|c|c|c|c|c|}
\hline \multirow[t]{2}{*}{ Country } & \multicolumn{3}{|c|}{ Trend 1} & \multicolumn{3}{|c|}{ Trend 2} & \multicolumn{3}{|c|}{ Trend 3} & \multicolumn{3}{|c|}{ Trend 4} \\
\hline & Years & EAPC & $95 \% \mathrm{Cl}$ of EAPC & Years & EAPC & $95 \% \mathrm{Cl}$ of EAPC & Years & EAPC & $95 \% \mathrm{Cl}$ of EAPC & Years & EAPC & $95 \% \mathrm{Cl}$ of EAPC \\
\hline$U_{S A}^{\#}$ & 2000-2005 & -2.2 & $-2.4--1.9$ & $2005-2010$ & -2.7 & $-3--2.3$ & 2010-2014 & -3.6 & $-4.1--3.1$ & 2014-2017 & -5.1 & $-5.6--4.6$ \\
\hline Cyprus & 2004-2016 & 1.4 & $-0.3-3.2$ & & & & & & & & & \\
\hline Austria & 2000-2013 & -1.4 & $-1.7--1.1$ & 2013-2017 & -3.5 & $-5.3--1.6$ & & & & & & \\
\hline Belgium & $2000-2010$ & -1.6 & $-2--1.2$ & 2010-2016 & -4.2 & $-5.1--3.3$ & & & & & & \\
\hline Bulgaria & 2000-2006 & 3 & $1.6-4.5$ & 2006-2015 & -0.7 & $-1.5-0$ & & & & & & \\
\hline Croatia & 2000-2002 & -8.9 & $-12.8--4.9$ & 2002-2016 & -0.9 & $-1.1--0.7$ & & & & & & \\
\hline Czech Republic & 2000-2017 & -3.3 & $-3.6--3.1$ & & & & & & & & & \\
\hline Denmark & 2000-2015 & -2.1 & $-2.4--1.7$ & & & & & & & & & \\
\hline Estonia & 2000-2016 & -1.7 & $-2.3--1.1$ & & & & & & & & & \\
\hline Finland & 2000-2016 & -1.9 & $-2.3--1.5$ & & & & & & & & & \\
\hline France & $2000-2006$ & -0.3 & $-0.7-0$ & 2006-2014 & -1.5 & $-1.7--1.3$ & & & & & & \\
\hline Germany & 2000-2006 & -2.2 & $-2.5--1.9$ & $2006-2013$ & -1.1 & $-1.4--0.8$ & 2013-2016 & -2.5 & $-3.4-1.5$ & & & \\
\hline Greece & 2000-2011 & -0.4 & $-0.8-0$ & 2011-2014 & 2.8 & $-2.8-8.7$ & 2014-2016 & -3.2 & $-8.4-2.3$ & & & \\
\hline Hungary & 2000-2017 & -1.4 & $-1.7--1.1$ & & & & & & & & & \\
\hline Ireland & 2000-2015 & -1.4 & $-2--0.9$ & & & & & & & & & \\
\hline Italy & 2000-2012 & -1.9 & $-2--1.7$ & $2012-2015$ & -3.3 & $-4.3--2.4$ & & & & & & \\
\hline Latvia & 2000-2013 & -1.1 & $-1.7--0.5$ & 2013-2015 & -9.6 & $-20-2.1$ & & & & & & \\
\hline Lithuania & 2000-2017 & -1.4 & $-1.8--1$ & & & & & & & & & \\
\hline Netherlands & 2000-2016 & -2.5 & $-2.7--2.2$ & & & & & & & & & \\
\hline Poland & 2000-2015 & -1 & $-1.9--0.1$ & 2005-2016 & -2.3 & $-2.5--2$ & & & & & & \\
\hline Portugal & 2000-2016 & 0.5 & $0.1-0.8$ & & & & & & & & & \\
\hline Romania & 2000-2010 & 0.6 & $0.2-0.9$ & 2010-2017 & -0.5 & $-1.1-0.1$ & & & & & & \\
\hline Slovakia & 2000-2014 & -2.2 & $-2.6--1.7$ & & & & & & & & & \\
\hline Slovenia & 2000-2015 & -1.8 & $-2.4--1.2$ & & & & & & & & & \\
\hline Spain & 2000-2003 & 0.2 & $-1.3-1.7$ & 2003-2011 & -1.2 & $-1.6--0.8$ & 2011-2015 & -2.3 & $-3.2--1.4$ & & & \\
\hline Sweden & 2000-2005 & 0.5 & $-1.5-2.6$ & 2005-2016 & -2.5 & $-3.1--1.9$ & & & & & & \\
\hline UK & 2001-2009 & -1.7 & $-2--1.4$ & 2009-2016 & -2.5 & $-2.9--2.2$ & & & & & & \\
\hline
\end{tabular}



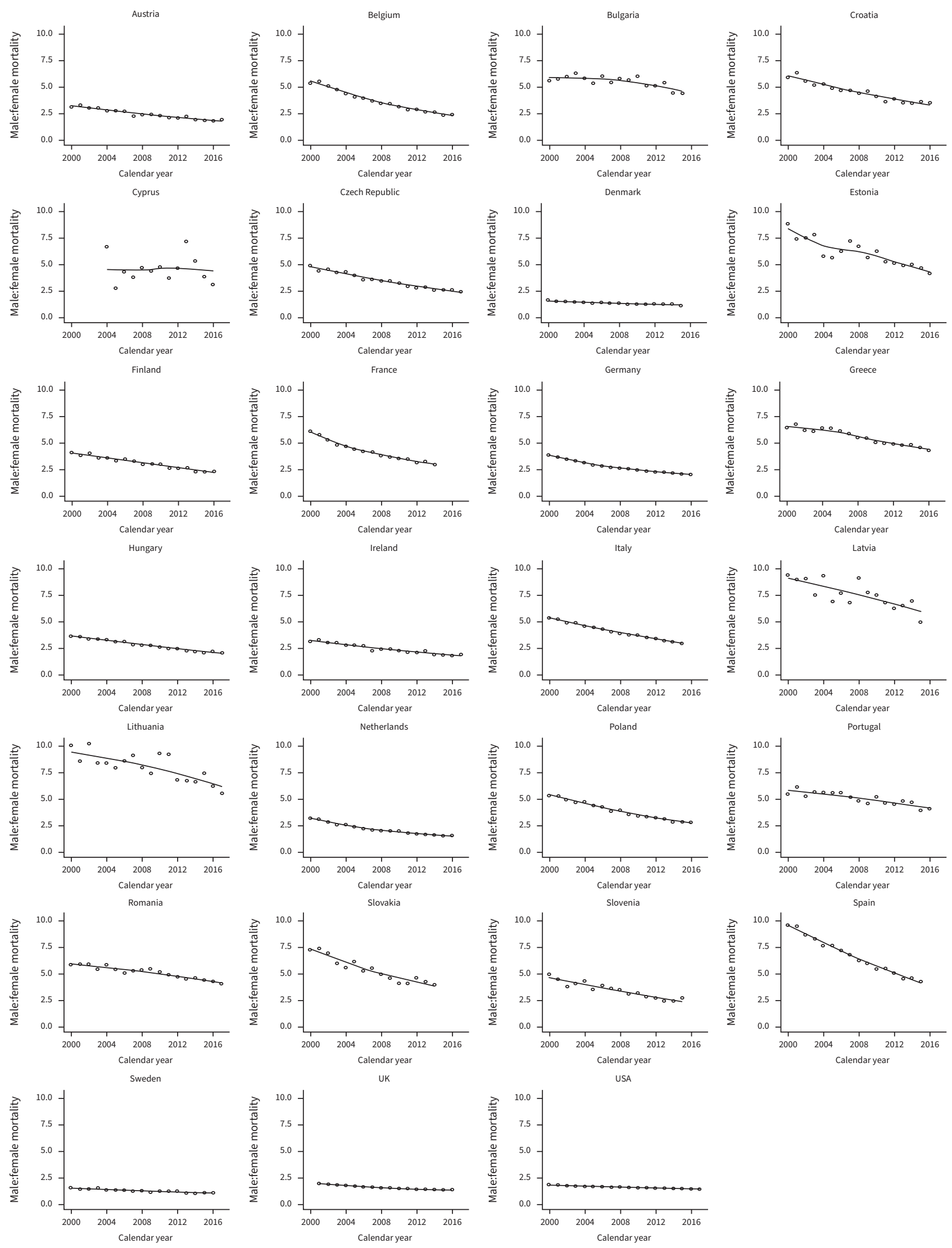

FIGURE 3 Trends in the ratio of male:female mortality for lung cancer between 2001 and 2017. 


\begin{tabular}{|c|c|c|c|c|c|c|c|c|c|c|c|c|}
\hline \multirow[t]{2}{*}{ Country } & \multicolumn{3}{|c|}{ Trend 1} & \multicolumn{3}{|c|}{ Trend 2} & \multicolumn{3}{|c|}{ Trend 3} & \multicolumn{3}{|c|}{ Trend 4} \\
\hline & Years & EAPC & $95 \% \mathrm{Cl}$ of EAPC & Years & EAPC & $95 \% \mathrm{Cl}$ of EAPC & Years & EAPC & $95 \% \mathrm{Cl}$ of EAPC & Years & EAPC & $95 \% \mathrm{Cl}$ of EAPC \\
\hline USA $^{\#}$ & $2000-2003$ & 0.2 & $-0.7-1$ & $2003-2009$ & -1.1 & $-1.5--0.7$ & 2009-2014 & -2.2 & $-2.7--1.6$ & $2014-2017$ & -4.2 & $-5--3.4$ \\
\hline Cyprus & 2004-2016 & & $-2-5.4$ & & & & & & & & & \\
\hline Austria & 2000-2017 & 1.8 & $1.3-2.3$ & & & & & & & & & \\
\hline Belgium & 2000-2011 & 4.2 & $3.5-4.8$ & 2011-2016 & -0.1 & $-2.1-1.9$ & & & & & & \\
\hline Bulgaria & 2000-2015 & 2.2 & $1.5-2.9$ & & & & & & & & & \\
\hline Croatia & 2000-2016 & 2.4 & $1.8-3$ & & & & & & & & & \\
\hline Czech Republic & 2000-2017 & 0.7 & $0.4-1.1$ & & & & & & & & & \\
\hline Denmark & 2000-2005 & 1.7 & $-0.4-3.9$ & 2005-2015 & -0.9 & $-1.7--0.2$ & & & & & & \\
\hline Estonia & 2000-2016 & 2 & $1.2-2.8$ & & & & & & & & & \\
\hline Finland & $2000-2016$ & 1.9 & $1.6-2.3$ & & & & & & & & & \\
\hline France & 2000-2005 & 6.6 & $5.1-8.1$ & 2005-2014 & 2.8 & $2.2-3.4$ & & & & & & \\
\hline Germany & 2000-2011 & 2.9 & $2.6-3.1$ & 2011-2016 & 1 & $0.2-1.8$ & & & & & & \\
\hline Greece & $2000-2005$ & 0.1 & $-1.5-1.7$ & 2005-2016 & 3.7 & $3.2-4.2$ & & & & & & \\
\hline Hungary & 2000-2017 & 2.1 & $1.7-2.5$ & & & & & & & & & \\
\hline Ireland & $2000-2006$ & 1.9 & $-0.1-3.8$ & 2006-2015 & -0.4 & $-1.5-0.6$ & & & & & & \\
\hline Italy & $2000-2015$ & 1.9 & $1.8-2.1$ & & & & & & & & & \\
\hline Latvia & 2000-2015 & 1.2 & $0.1-2.4$ & & & & & & & & & \\
\hline Lithuania & 2000-2017 & 1.1 & $0.3-1.9$ & & & & & & & & & \\
\hline Netherlands & 2000-2007 & 4.2 & $3.4-5$ & $2007-2016$ & 0.8 & $0.3-1.4$ & & & & & & \\
\hline Poland & 2000-2016 & 2.4 & $2.1-2.7$ & & & & & & & & & \\
\hline Portugal & 2000-2016 & 2.6 & 2.1-3.1 & & & & & & & & & \\
\hline Romania & 2000-2017 & 2.3 & $2-2.6$ & & & & & & & & & \\
\hline Slovakia & 2000-2014 & 2.4 & $1.7-3.1$ & & & & & & & & & \\
\hline Slovenia & 2000-2015 & 2.5 & $2-3.1$ & & & & & & & & & \\
\hline Spain & 2000-2015 & 4.4 & $4.1-4.7$ & & & & & & & & & \\
\hline Sweden & 2000-2005 & 3.5 & $1.2-5.9$ & 2005-2016 & -0.5 & $-1.2-0.2$ & & & & & & \\
\hline UK & 2001-2008 & 1.7 & $1.1-2.3$ & $2008-2016$ & -0.7 & $-1.2--0.2$ & & & & & & \\
\hline
\end{tabular}


TABLE 4 Post hoc analysis of the male-to-female ratio of lung cancer mortality

\begin{tabular}{|c|c|c|c|c|}
\hline \multirow[t]{2}{*}{ Country } & \multicolumn{2}{|c|}{ Start point } & \multicolumn{2}{|c|}{ End point } \\
\hline & Year of diagnosis & Sex ratio & Year of diagnosis & Sex ratio \\
\hline Spain & 2000 & 9.53 & 2015 & 4.27 \\
\hline Estonia & 2000 & 8.82 & 2016 & 4.16 \\
\hline Lithuania & 2000 & 10.07 & 2017 & 5.51 \\
\hline Latvia & 2000 & 9.44 & 2015 & 5.00 \\
\hline Cyprus & 2004 & 6.65 & 2016 & 3.08 \\
\hline Slovakia & 2000 & 7.25 & 2014 & 3.93 \\
\hline France & 2000 & 6.06 & 2014 & 2.91 \\
\hline Belgium & 2000 & 5.37 & 2016 & 2.41 \\
\hline Poland & 2000 & 5.32 & 2016 & 2.80 \\
\hline Czech Republic & 2000 & 4.91 & 2017 & 2.43 \\
\hline Croatia & 2000 & 5.92 & 2016 & 3.54 \\
\hline Italy & 2000 & 5.35 & 2015 & 2.97 \\
\hline Slovenia & 2000 & 4.94 & 2015 & 2.74 \\
\hline Greece & 2000 & 6.39 & 2016 & 4.26 \\
\hline Germany & 2000 & 3.82 & 2016 & 1.99 \\
\hline Romania & 2000 & 5.85 & 2017 & 4.05 \\
\hline Finland & 2000 & 4.06 & 2016 & 2.31 \\
\hline Netherlands & 2000 & 3.14 & 2016 & 1.54 \\
\hline Hungary & 2000 & 3.65 & 2017 & 2.08 \\
\hline Portugal & 2000 & 5.45 & 2016 & 4.06 \\
\hline Austria & 2000 & 3.15 & 2017 & 1.92 \\
\hline Bulgaria & 2000 & 5.62 & 2015 & 4.40 \\
\hline Ireland & 2000 & 2.13 & 2015 & 1.52 \\
\hline UK & 2001 & 1.96 & 2016 & 1.39 \\
\hline Denmark & 2000 & 1.63 & 2015 & 1.13 \\
\hline Sweden & 2000 & 1.58 & 2016 & 1.10 \\
\hline USA $^{\#}$ & 2000 & 1.86 & 2017 & 1.45 \\
\hline
\end{tabular}

lung cancer mortality across EU countries and the USA. To our knowledge, this is the first paper to compare the trends in lung cancer mortality rates across the EU and the USA using data obtained from both the CDC WONDER and WHO mortality databases.

Possible contributors to the observed trends

A number of population-level and public health efforts within cancer control programmes have been implemented in attempts to improve both the prevention of and mortality from lung cancer in the USA and EU countries. Being aware that the present data is observational, discussion as to the contributors to the observed trends in mortality should be cautious; however, likely contributors to the reducing rates of lung cancer mortality include the development and implementation of cancer registries across the USA and EU countries, changes in smoking behaviours, the advent of newer treatment modalities and the development of screening programmes.

Cancer Registries provide a means to identify high-risk patient cohorts and, therein, define patients to be targeted for resource allocation to enable both prevention strategies and early diagnosis and treatment. Currently, there are 55 cancer registries in the USA, covering 94\% of the population, the first of which was the Surveillance, Epidemiology and End Results (SEER) Program (established in 1973) [16]. Cancer Registries have been an essential adjunct to the implementation of high-quality lung cancer screening programmes [17], and their use has previously been suggested to reduce population-level mortality, which may be contributory to the observed earlier improvements in lung cancer mortality in the USA compared to the majority of European nations [17]. Cancer Registries, which also enable identification of geographical differences in treatment outcomes, have progressed consistently since 1990 and have increased to nearly 200 in Europe [18], covering 60\% of the European population. However, significant disparities of population coverage by cancer registries exist across EU countries, especially in south-eastern Europe [18]. Countries like Hungary (1999), Croatia (2001) and Poland (1999), which still have high 
mortality rates, incorporated cancer registries late as compared to other countries like Denmark (1982) and Sweden (1958), which have low mortality rates. Furthermore, we saw that Baltic countries like Lithuania (1993) and Latvia (2000) also started their registries later. Newer treatment modalities, including immunomodulators, have become a feature of lung cancer therapy since 2014 and have resulted in improvements in mortality, with further data pertaining to the impact of these novel therapies awaited [19].

The tobacco epidemic has remained closely associated with the incidence and mortality of lung cancer and has been a focus of considerable attention and intervention. Population-level efforts to reduce smoking prevalence have also been shown to contribute to reductions in lung cancer mortality [20], and peaks in lung cancer mortality have mirrored the smoking epidemic [20]. European countries have started implementing policies for outdoor smoking as well, although the majority of these laws have failed to implement smoke-free outdoor areas. A few countries adopted these policies earlier [21]. Countries with higher mortality rates like Hungary (ASDR of 64.5 for males and 31 for females), Croatia (54.8 for males, 30.6 for females), Poland (53 for males, 18.9 for females), Greece (50 for males, 11.8 for females) and Romania (47.5 for males,11.7 for females) still do not have policies for a ban on outdoor smoking [22]. Currently, Sweden is one of the only countries in Europe with a complete ban on outdoor smoking that has very low mortality rates (17.3 for males, 7.6 for females) [22].Countries with a high Human Development Index with early initiatives to reduce smoking prevalence have shown a steady reduction in lung cancer [23]. Interestingly, these same countries have also observed a disparity in smoking cessation by sex [20], which may contribute to the differential lung cancer mortality trends observed among men and women in the present analysis.

More recently, lung cancer screening has contributed to improvements in the diagnosis of early-stage lung cancer [24]. Large population screening trials in the USA and Europe have highlighted the benefits of lung cancer screening on mortality rates and have also demonstrated important sex disparities. The National Lung Screening Trial (NLST) carried out in the USA compared low-dose computed tomography (LDCT) scanning versus chest radiography in high-risk individuals, reporting a $20 \%$ reduction in lung cancer mortality for LDCT-screened participants, leading to a grade B recommendation from the US Preventive Services Task Force in 2013 indicating high certainty that there will be moderate net benefit [25]. At the same time, the NELSON trial in Europe also showed that the cumulative rate ratio for death from lung cancer at 10 years was 0.76 (95\% CI $0.61-0.94 ; p=0.01$ ) in the screening group [26]. German Lung Cancer Screening Intervention (LUSI) results were also in line with these results with a HR of 0.74 (95\% CI 0.46-1.19; $\mathrm{p}=0.21$ ) [27]. The evidence supporting the benefits of screening for lung cancer outcomes has led the European Round Table to recommend that all National Healthcare policymakers implement lung cancer screening in Europe. We will be able to study its effects on the general population in the coming decade [28].

Also, socioeconomic disparities are associated with a more delayed diagnosis, which plays a significant role in the outcomes of lung cancer. It is also linked with decreased chances of receiving treatment [29]. When healthcare costs per person for lung cancer were compared among different European countries in 2009, it was found that countries like Hungary (EUR 4) and Poland (EUR 5) are spending less as compared to the EU average (EUR 8) or Sweden (EUR 8) [30]. When comparing the USA and western Europe between 1982 and 2010, the cost of lung cancer care exceeded that in Europe by USD 406 billion. Despite that, the USA still had a high ASDR. Analysis showed that higher spending in cancer care could reduce death rates for breast, prostate and colorectal cancer but had no effect on lung cancer rates [31]. This suggests that higher spending alone cannot decrease mortality, and there needs to be a multifactorial approach.

The gender gaps

We also observed that the overall male-to-female ratio steadily decreased in all the countries throughout the observation period. Various plausible explanations exist, including the smoking pandemic [32]. In most countries, female smoking has lagged behind male smoking, and so have the resulting mortality peaks due to earlier cultural prohibition [20]. This has caused smoking rates in older women to continue to rise for most countries in Europe, with its corresponding impact on lung cancer mortality [33, 34]. In the USA, the smoking incidence has decreased in both males and females. The decline is comparatively slower in females, which can be correlated to a late decline in female mortality trend compared to males in our study [32]. It has also been found that women might be more susceptible to carcinogens in cigarettes [35, 36]. The gastrin-releasing peptide receptor gene found on the $\mathrm{X}$ chromosome has been linked with proliferation of bronchial cells when activated. This gene is activated more often and earlier in females when exposed to carcinogens due to smoking [37]. 
A recent study reported the unique finding that females were $36 \%$ less likely to discuss lung cancer screening with their healthcare provider than males [38]. Various trials have shown encouraging results to promote lung cancer screening in females. The NLST reported minor evidence of differential benefit in females with lower relative risks for small cell and squamous cell carcinoma in females on early detection [39]. At the same time, subgroup analysis of the NELSON trial of Europe identified screening to be more effective at decreasing mortality in high-risk females (HR 0.39-0.61) than in males (HR 0.59-0.91) over 10 years [26]. The German LUSI study reported up to 69\% reduction in lung cancer mortality among females (HR 0.31; 95\% CI 0.10-0.96), as compared to 6\% in males (HR 0.94; 95\% CI 0.54-1.61) [27]. The PLCO trial involving 77911 females demonstrated a protective effect of hormone replacement therapy against lung cancer development and mortality [40]. Efforts are now needed to increase awareness among women.

\section{The Baltics}

As seen in figures 2 and 3, Lithuania, Latvia and Estonia had fluctuations in trends in mortality rates. Various plausible explanations exist. Baltic states have unique environmental exposure due to the Chernobyl effect. These countries have a population that was directly exposed to radiation, with documented effects [41], which may predispose them to other types of cancer (i.e. thyroid) rather than lung [42]. The analyses on this matter are beyond the scope of this paper, but it still represents a caveat when interpreting the results [35, 42]. Similar to the Baltics, Portugal and Cyprus showed an increasing trend. An analysis from 2009 showed that Portugal was still entering the third stage of the smoking epidemic [43]. Also, other cancers, such as colorectal, breast and prostate, are more prevalent in Portugal than lung cancer [44]. Therefore, a strategic approach might be needed in managing lung cancer mortality in a similar way to other cancers. Similarly, in the Baltic countries, more awareness exists for thyroid cancer screening than other cancers [41]. A unified approach to all cancers is needed for these countries.

\section{Strengths and limitations}

The strengths of this investigation include the use of annual mortality data collected from national surveillance statistics from the WHO and the CDC. These data have made it possible to assess population-level trends over an extended observation period, allowing comparisons in trends rather than absolute annual mortality rates. Despite this study's strengths, there are a number of limitations that should be considered when interpreting the results. The US ASDRs were based on the US Standard Population, whereas the World Standard Population was utilised for the ASDR calculation for European nations. Therefore, these results cannot be directly compared. However, one notable strength of using longitudinal data is commenting on overall trends within individual countries after standardisation and reporting these differences between health systems. Second, we did not attempt to assess the prevalence of morbidity associated with lung cancer as our primary aim was to better understand changes in mortality trends; there may be substantial differences in the prevalence of lung cancer between countries that we cannot elucidate in this current report. Third, we combined subtypes of lung cancer in our findings as mortality data are not recorded separately for each pathological subtype. It is also found that the number of deaths from lung cancer nationally in the USA was lower than that reported by death certificate data [32]. Finally, as with any observational study, causal statements regarding the observed trends cannot be made. The discussion is provided to assist future researchers, policymakers and public health experts in focusing their efforts.

\section{Conclusion}

This report reveals decreasing trends in lung cancer mortality in Europe and the USA for men between 2000 and 2017. For women, many European countries demonstrate a gradually rising trend in lung cancer mortality over the same time period. There is a persistent but decreasing sex-mortality gap across Europe and the USA. Future efforts should be targeted at aligning policy and public health interventions to further guide implementation strategies for cancer registries, smoking cessation programmes and large-scale lung cancer screening with gender equity in mind.

Acknowledgements: Prior abstract presentations: "Trends in lung cancer mortality between 2001 and 2017: an observational study in USA and EU", 2 June 2020, presented at ASCO conference; "Persistent sex-difference in lung cancer mortality between 2001 and 2017 in the US and EU", 17 September 2020, presented at European Society of Medical Oncology conference.

Provenance: Submitted article, peer reviewed.

Author contributions: Each of the authors significantly contributed to this manuscript. C. Jani, J.D. Salciccioli, H. Singh and C.C. Thomson made significant contributions to the concept and design of this paper. J.D. Salciccioli, 
D.C. Marshall and C. Jani were significantly involved in the statistical analysis. C. Jani, D.C. Marshall, H. Singh, R. Goodall, J. Shalhoub, O. Al Omari, J.D. Salciccioli and C.C. Thomson were greatly involved in drafting manuscript. J. Shalhoub, J.D. Salciccioli and C.C. Thomson were involved in critical revision of the manuscript and contributed vital intellectual content. C. Jani (corresponding author and guarantor) takes responsibility for the content of the manuscript, including the data and analysis.

Conflict of interest: The authors do not have any conflicts of interest or any disclosures.

References

1 CDC. United States cancer statistics: data visualizations. 2018; 27. https://www.cdc.gov/cancer/uscs/dataviz/ index.htm Date last accessed: 15 August 2021.

2 Xu J, Kochanek KD, Murphy SL, et al. Mortality in the United States, 2012. NCHS Data Brief 2014; 168: 1-8.

3 World Health Organization. Fact Sheets. Geneva: World Health Organization; 2020. www.who.int/news-room/ fact-sheets/detail/cancer Date last accessed: 10 July 2021.

4 Zhang Y, Ren JS, Huang HY, et al. International trends in lung cancer incidence from 1973 to 2007. Cancer Med 2018; 7: 1479-1489.

5 Mousavi SM, Schmid S, Cerny T, et al. Lung cancer and smoking trends in the young in Switzerland: a study based on data of the National Institute for Cancer Epidemiology and Registration and of the Swiss Health Surveys. Swiss Med Wkly 2018; 148: w14708.

6 Hartley A, Marshall DC, Salciccioli JD, et al. Trends in mortality from ischemic heart disease and cerebrovascular disease in Europe: 1980 to 2009. Circulation 2016; 133: 1916-1926.

7 Salciccioli JD, Marshall DC, Shalhoub J, et al. Respiratory disease mortality in the United Kingdom compared with EU15+ countries in 1985-2015: observational study. BMJ 2018; 363: k4680.

8 Marshall DC, Salciccioli JD, Shea BS, et al. Trends in mortality from idiopathic pulmonary fibrosis in the European Union: an observational study of the WHO mortality database from 2001-2013. Eur Respir J 2018; 51: 1701603.

9 World Health Organization. 2014. Census and Civil Registration Coverage Data by Country. http://apps.who. int/gho/data/node.main.121?lang=enWHO.\%202014.\%20WHO Date last accessed: 3 May 2020.

10 European Commission. EU member states. 2020. https://european-union.europa.eu/principles-countrieshistory/country-profiles_en Date last accessed: 10 July 2021.

11 Centers for Disease Control and Prevention, National Center for Health Statistics. Underlying Cause of Death' '1999-2018 on CDC WONDER Online Database, released in 2020. Data are from the Multiple Cause of Death Files, 1999-2018, as' 'compiled from data provided by the 57 vital statistics jurisdictions through the Vital Statistics Cooperative Program. http://wonder.cdc.gov/ucd-icd10.html Date last accessed: 6 May 020.

12 Friede A, Reid JA, Ory HW. CDC WONDER: a comprehensive on-line public health information system of the Centers for Disease Control and Prevention. Am J Public Health 1993; 83: 1289-1294.

13 Friede A, Rosen DH, Reid JA. CDC WONDER: a cooperative processing architecture for public health. J Am Med Inform Assoc 1994; 1: 303-312.

14 Ahmad OB, Boschi-Pinto C, Lopez AD, et al. Age standardization of rates: a new WHO standard. www.who.int/ healthinfo/paper31.pd Date last accessed: 10 July 2021.

$15 \mathrm{Kim}$ HJ, Fay MP, Feuer EJ, et al. Permutation tests for Joinpoint regression with applications to cancer rates. Stat Med 2000; 19: 335-351.

16 White MC, Babcock F, Hayes NS, et al. The history and use of cancer registry data by public health cancer control programs in the United States. Cancer 2017; 123: Suppl 24, 4969-4976.

17 Parkin DM. The role of cancer registries in cancer control. Int J Clin Oncol 2008; 13: 102-111.

18 Forsea AM. Cancer registries in Europe: going forward is the only option. Ecancermedicalscience 2016; $10: 641$.

19 Forde PM, Chaft JE, Pardoll DM. Neoadjuvant PD-1 blockade in resectable lung cancer. N Engl J Med 2018; 379: e14.

20 Thun M, Peto R, Boreham J, et al. Stages of the cigarette epidemic on entering its second century. Tob Control 2012; 21: 96-101.

21 Martinez C, Guydish J, Robinson G, et al. Assessment of the smoke-free outdoor regulation in the WHO European Region. Prev Med 2014; 64: 37-40.

22 Smokefree Map. Smoke free partnership foundation. www.smokefreepartnership.eu/smokefree-map Date last accessed: 10 July 2021.

23 Cl5plus. Cancer Incidence in Five Continents time trends. Lyon: International Agency for Research on Cancer; 2020. https://ci5.iarc.fr/Default.aspx Date last accessed: 10 July 2021.

24 Kowall B, Jockel KH, Stang A. [Lung cancer screening: current trends]. Bundesgesundheitsblatt Gesundheitsforschung Gesundheitsschutz 2018; 61: 1551-1558.

25 Aberle D, Adams A, Berg C, et al. Reduced lung-cancer mortality with low-dose computed tomographic screening. N Engl J Med 2011; 365: 395-409. 
de Koning HJ, van der Aalst CM, de Jong PA, et al. Reduced lung-cancer mortality with volume CT screening in a randomized trial. N Engl J Med 2020; 382: 503-513.

Becker N, Motsch E, Trotter A, et al. Lung cancer mortality reduction by LDCT screening: results from the randomized German LUSI trial. Int J Cancer 2020; 146: 1503-1513.

Field $\mathrm{JK}$, deKoning $\mathrm{H}$, Oudkerk $\mathrm{M}, t$ al. Implementation of lung cancer screening in Europe: challenges and potential solutions: summary of a multidisciplinary roundtable discussion. ESMO Open 2019; 4: e000577.

Ebner PJ, Ding L, Kim AW, et al. The effect of socioeconomic status on treatment and mortality in non-small cell lung cancer patients. Ann Thorac Surg 2020; 109: 225-232.

Luengo-Fernandez R, Leal J, Gray A, et al. Economic burden of cancer across the European Union: a population-based cost analysis. Lancet Oncol 2013; 14: 1165-1174.

Soneji S, Yang J. New analysis reexamines the value of cancer care in the United States compared to Western Europe. Health Aff (Millwood) 2015; 34: 390-397.

Howlader N, Forjaz G, Mooradian MJ, et al. The effect of advances in lung-cancer treatment on population mortality. N Engl J Med 2020; 383: 640-649.

$\mathrm{Ng} \mathrm{M}$, Freeman MK, Fleming TD, et al. Smoking prevalence and cigarette consumption in 187 countries, 1980-2012. Jama 2014; 311: 183-192.

Torre LA, Siegel RL, Ward EM, et al. International variation in lung cancer mortality rates and trends among women. Cancer Epidemiol Biomarkers Prev 2014; 23: 1025-1036.

Fontham ET, Correa P, Reynolds P, et al. Environmental tobacco smoke and lung cancer in nonsmoking women. A multicenter study. JAMA 1994; 271: 1752-1759.

Wang TJ, Zhou BS, Shi JP. Lung cancer in nonsmoking Chinese women: a case-control study. Lung Cancer 1996; 14: Suppl 1, S93-S98.

Shriver SP, Bourdeau HA, Gubish CT, et al. Sex-specific expression of gastrin-releasing peptide receptor: relationship to smoking history and risk of lung cancer. J Natl Cancer Inst 2000; 92: 24-33.

Warner ET, Lathan CS. Race and sex differences in patient provider communication and awareness of lung cancer screening in the health information National Trends Survey, 2013-2017. Prev Med 2019; 124: 84-90.

Pinsky PF, Church TR, Izmirlian G, et al. The national lung screening trial: results stratified by demographics, smoking history, and lung cancer histology. Cancer 2013; 119: 3976-3983.

Abdel-Rahman O. Lung cancer incidence and mortality in relationship to hormone replacement therapy use among women participating in the PLCO trial: a post hoc analysis. Int J Clin Oncol 2020; 25: 885-891.

1 Rahu K, Hakulinen T, Smailyte G, et al. Site-specific cancer risk in the Baltic cohort of Chernobyl cleanup workers, 1986-2007. Eur J Cancer 2013; 49: 2926-2933.

2 Samet JM, de Gonzalez AB, Dauer LT, et al. Gilbert W. Beebe symposium on 30 years after the Chernobyl accident: current and future studies on radiation health effects. Radiat Res 2018; 189: 5-18.

4 Alves L, Bastos J, Lunet N. Trends in lung cancer mortality in Portugal (1955-2005). Rev Port Pneumol 2009; 15: $575-587$

4 World Health Organization. Globocon 2020 Statistics for Portugal. https:/gco.iarc.fr/today/data/factsheets/ populations/620-portugal-fact-sheets.pdf Date last accessed: 10 July 2021. 